\title{
Optimisation of irinotecan dose in the treatment of patients with metastatic colorectal cancer after 5-FU failure: results from a multinational, randomised phase II study
}

\author{
E Van Cutsem ${ }^{*, 1}$, L Dirix ${ }^{2}$, J-L Van Laethem ${ }^{3}$, S Van Belle ${ }^{4}$, M Borner ${ }^{5}$, M Gonzalez Baron ${ }^{6}$, A Roth ${ }^{7}$, R Morant $^{8}$, \\ E Joosens', G Gruia ${ }^{10}$, D Sibaud" and H Bleiberg ${ }^{12}$ \\ 'University Hospital Gasthuisberg, 3000 Leuven, Belgium; ${ }^{2}$ St Augustinus Ziekenhuis, 2610 Wilrijk, Belgium; ${ }^{3}$ ULB Hospital, Erasme, 1070 Brussels, \\ Belgium; ${ }^{4}$ University Hospital Gent, 9000 Gent, Belgium; ${ }^{5}$ Institut Med Onkologie, Inselspital, 3010 Bern, Switzerland; ${ }^{6}$ Hopital La Paz de Madrid, 28000 \\ Madrid, Spain; ${ }^{7}$ Hopital de Genève, Geneva 121 I. Switzerland; ${ }^{8}$ Kantonspital St Gallen, 9007 St Gallen, Switzerland; ${ }^{9}$ AZ Middelheim, 2020 Antwerp, \\ Belgium; ${ }^{10}$ Pfizer, New York, NY 10017 , USA; "'Aventis Pharma, Antony Cedex 92165, France; ${ }^{12}$ Institute J Bordet, 1000 Brussels, Belgium
}

\begin{abstract}
Although irinotecan $350 \mathrm{mg} \mathrm{m}^{-2}$ is a standard option for relapsed/refractory advanced colorectal cancer, there is some evidence that suggests that a higher dose may be more effective, with acceptable tolerability, following 5-fluorouracil (5-FU). This study assessed the optimal dosing strategy for irinotecan, along with treatment efficacy and safety. A total of 164 patients with metastatic colorectal cancer progressing after failure on 5 -FU or raltitrexed received either $350 \mathrm{mg} \mathrm{m}^{-2}$ irinotecan (Group $\mathrm{A} ; n=36$ ) or 250,350 or $500 \mathrm{mg} \mathrm{m}^{-2}$, according to individual patient tolerance (Group B; $n=62$ ) or based on risk factor optimisation (Group C; $n=66$ ). There were no complete responses. There was a trend towards a higher overall response rate in Group B (I 3\%) than in Groups A (8\%) and C (9\%). Tumour control growth rate was high in all three groups: $58 \%$ in group A, $60 \%$ in Group B and $50 \%$ in Group C. A total of 34\% of patients in Group B and 9\% in Group C were able to receive a dose of $500 \mathrm{mg} \mathrm{m}^{-2}$. Median duration of response and time to progression were significantly longer in Groups A and B compared with Group C. No significant between-group differences for any adverse events were seen, although there was a small trend towards better tolerability in Group B. Individual dose escalation based on patient tolerance may allow more patients to receive a higher irinotecan dose without causing additional toxicity and can be an appropriate patient management strategy.
\end{abstract}

British Journal of Cancer (2005) 92, 1055-1062. doi:I0.1038/sj.bjc.6602462 www.bjcancer.com

Published online 8 March 2005

(c) 2005 Cancer Research UK

Keywords: colorectal cancer; CPT-II; dose optimisation; irinotecan

Irinotecan (CPT-11, Campto ${ }^{\circledR}$ ) - a semisynthetic, water-soluble derivative of the plant alkaloid camptothecin - is the standard of care in the treatment of advanced colorectal cancer when 5fluorouracil (5-FU)-based therapy has failed (Cunningham et al, 2001). Phase II trials have demonstrated objective response rates of $16-27 \%$ in pretreated patients, with stabilisation of disease in a further $40-60 \%$ of patients (Rougier et al, 1997; Van Cutsem et al, 1999). Median overall survival rates of up to 10 months are achievable when irinotecan is used in relapsed/refractory colorectal cancer (Shimada et al, 1993; Rothenberg et al, 1996, 1999; Pitot et al, 1997; Rougier et al, 1997; Van Cutsem et al, 1999). Two European phase III trials investigating the efficacy and safety of irinotecan, following 5-FU failure in advanced colorectal cancer, have demonstrated significant improvements in survival compared with best supportive care and 5-FU (Cunningham et al, 1998;

\footnotetext{
* Correspondence: Professor E Van Cutsem, University Hospital Gasthuisberg, Herestraat 49, 3000 Leuven, Belgium;

E-mail: eric.vancutsem@uz.kuleuven.ac.be

Received 15 September 2004; revised 6 January 2005; accepted 20 January 2005; published online 8 March 2005
}

Rougier et al, 1998). The main adverse events accompanying treatment with irinotecan in these trials were diarrhoea, neutropenia, fatigue, nausea and vomiting.

Although $350 \mathrm{mg} \mathrm{m}^{-2}$ as an intravenous infusion every 3 weeks is the standard recommended dosage of irinotecan, pharmacokinetic parameters of irinotecan-lactone and the active metabolite SN-38-lactone vary between individuals (Xie et al, 2002). This may be attributed to differences in the levels of the enzymes that metabolise irinotecan, notably carboxylesterase for SN-38. Furthermore, the variable interindividual patient exposure to $\mathrm{SN}$ 38 has been identified as an important determinant of toxicity (Mathijssen et al, 2002).

At the same time, there is convincing evidence of a doseresponse relationship, and therefore a rationale for increasing doses when possible. In a phase I trial by Abigerges et al (1995), there were two recommended doses: $350 \mathrm{mg} \mathrm{m}^{-2}$ without highdose loperamide and $600 \mathrm{mg} \mathrm{m}^{-2}$ with high-dose loperamide. With the exception of one responder treated at $260 \mathrm{mg} \mathrm{m}^{-2}$, all objective responses were observed at dose levels above $350 \mathrm{mg} \mathrm{m}^{-2}$. Merrouche et al (1997) provided further support for this from a phase I trial in which an increased tumour response was seen at an irinotecan dose level of $500 \mathrm{mg} \mathrm{m}^{-2}$. 
Thus, these data suggest that a fixed-dose strategy for administration of irinotecan may not be optimal for all patients, thereby comprising treatment. The interindividual variability in pharmacokinetic parameters and dose-response relationship provided the rationale for investigating a dose optimisation strategy for irinotecan (Chabot et al, 1995). The present study investigated different strategies, using doses of irinotecan up to $500 \mathrm{mg} \mathrm{m}^{-2}$, as single-agent therapy in the treatment of patients with metastatic colorectal cancer resistant to 5-FU.

\section{METHODS}

\section{Patients}

Eligibility criteria included metastatic, histologically proven adenocarcinoma of the colon or rectum progressing on 5-FUbased chemotherapy (adjuvant and/or palliative); administration of $\leqslant 25$-FU-based regimens in the adjuvant setting or $\leqslant 1$ in the palliative setting; World Health Organization (WHO) performance status (PS) of $\leqslant 2$; adequate haematological, renal and hepatic function. Exclusion criteria included prior treatment with topoisomerase-I inhibitors; evidence of central nervous system metastases; prior history of chronic diarrhoea; current infection; or any other serious illness or medical condition.

\section{Study design and conduct}

This was a prospective, randomised, multicentre, open-label, phase II study. The study was conducted in accordance with the Declaration of Helsinki (Hong Kong revision, 1989) and with the approval of the Ethics Committee (Institutional Review Board) at each participating centre. Written informed consent was obtained from each patient prior to his or her enrolment into the trial. An independent Monitoring Committee regularly assessed the safety and efficacy issues and reviewed the conduct of the study if needed. An External Response Review Committee (ERRC) assessed tumour responses without knowledge of the randomisation arm. The aim of the study was to determine the optimal dosing strategy in terms of efficacy and safety of single-agent irinotecan (by individual dose optimisation based on patient tolerance to treatment, or optimisation based on specific baseline risk factors) in the treatment of 5-FU-resistant patients with metastatic colorectal cancer. The primary efficacy endpoint was the overall response rate.

Dosing scenarios Patients were randomised to one of three groups (A, B and C (outlined below)), each group receiving irinotecan as a $30 \mathrm{~min}$ intravenous infusion scheduled every 21 days. This dosing interval could be extended to a maximum of 35 days in the event of persistent toxicity to allow satisfactory recovery from the previous cycle. Doses $<250 \mathrm{mg} \mathrm{m}^{-2}$ or $>500 \mathrm{mg} \mathrm{m}^{-2}$ were not used in this study; patients who exhibited significant toxicity at $250 \mathrm{mg} \mathrm{m}^{-2}$ were withdrawn from the study.

Group A was the reference group in which a fixed dose of $350 \mathrm{mg} \mathrm{m}^{-2}$ of irinotecan was administered on Day 1. In subsequent cycles, the dose of irinotecan could be decreased (but not increased) according to the presence of significant toxicity at this dose.

Groups B and C investigated dosing scenarios to select patients for whom the higher dose of irinotecan $\left(500 \mathrm{mg} \mathrm{m}^{-2}\right)$ could be optimally used. Patients randomised to Group B received irinotecan at a starting dose of $250 \mathrm{mg} \mathrm{m}^{-2}$ followed by increasing doses $\left(350\right.$ and $500 \mathrm{mg} \mathrm{m}^{-2}$ ) depending on the tolerance observed in the preceding cycle. In the event of significant toxicity, dose reductions were implemented.

In Group C, the irinotecan dose was based on protocol-defined toxicity risk factors identified at baseline: grade 3-4 neutropenia (bilirubin $>70 \%$ upper limit of normal (UNL), haemoglobin $<12 \mathrm{~g} \mathrm{dl}^{-1},>3$ organs involved) and/or grade 3-4 diarrhoea (PS $\geqslant 1$, creatinine $>70 \%$ UNL (Freyer et al, 2000)). Patients could be started at an irinotecan dose of $500 \mathrm{mg} \mathrm{m}^{-2}$ in the absence of toxicity risk factors. The starting dose of irinotecan was $350 \mathrm{mg} \mathrm{m}^{-2}$ in patients with one risk factor or one factor from each group, and $250 \mathrm{mg} \mathrm{m}^{-2}$ for patients with $>2$ risk factors or two factors from the same group. The dose was not escalated, but could be reduced to $250 \mathrm{mg} \mathrm{m}^{-2}$ in the event of significant treatment-emergent toxicity.

\section{Concomitant treatments and follow-up}

Antiemetic drugs were administered as premedication to irinotecan infusions. Atropine was permitted for acute anticholinergic symptoms and loperamide (or similar) for delayed diarrhoea. In addition, preventative oral antibiotic therapy (e.g. an oral fluoroquinolone) was administered to patients with persistent $(>48 \mathrm{~h}$ ) grade 4 diarrhoea or for diarrhoea associated with grade 3-4 neutropenia or fever. No granulocyte-colony-stimulating factor (G-CSF) support was allowed. All patients were followed until disease progression, unacceptable toxicity or death occurred, or the patient chose to withdraw from the trial. In all cases, in each group where toxicity necessitated a dose reduction, delay or study treatment termination, the patient was followed up until the event had resolved.

\section{Efficacy, safety and pharmacokinetic evaluations}

Tumour response rate, the primary efficacy end point, was measured according to WHO criteria and evaluated by the ERRC. Response was defined as complete (CR) plus partial (PR) response and as tumour growth control in terms of stabilisation of disease (PR plus no change/stable disease). Secondary efficacy variables were the duration of response and disease stabilisation, time to progression (TTP), time to treatment failure (TTF) and overall survival. The duration of response was measured from the first day of infusion of irinotecan to the first date that disease progression was noted or to the date of death for any reason. Time to progression was calculated from the date of randomisation to the first documented date of progression or the date of death for any reason. Time to treatment failure was the period between the date of randomisation and the date of tumour progression or treatment discontinuation for any reason. Survival was defined as the time between randomisation and death. Efficacy evaluations were performed using intent-to-treat (ITT) and per-protocol (eligible and evaluable) patient populations.

The safety population comprised all patients who had started at least one infusion of study treatment. Safety was assessed according to the National Cancer Institute Common Toxicity Criteria or, if this was not applicable, graded as mild, moderate, severe or life threatening. The safety analysis was based on the worst grade by patient and by cycle. Deaths during the trial and up to 30 days from the last infusion were recorded.

Pharmacokinetic evaluations were performed using a population approach (Chabot et al, 1995; Canal et al, 1996). At 30 min prior to infusion, and at $5 \mathrm{~min}$ and $3-4 \mathrm{~h}$ postinfusion (an additional sample was collected at $24 \mathrm{~h}$ postinfusion in some cases), three $5 \mathrm{ml}$ blood samples (plus one predrug sample) were taken for analysis at the first cycle of chemotherapy for Groups A and C, and at the first, second and third cycles for Group B. Plasma levels of irinotecan and SN-38 were measured using reverse-phase highperformance liquid chromatography with camptothecin as an internal standard. Peak plasma concentration $\left(C_{\max }\right)$ and the area under the plasma concentration-time curve (AUC) were calculated for both irinotecan and $\mathrm{SN}-38$. In addition, total body clearance was calculated for irinotecan, and the time to reach $C_{\max }$ $\left(t_{\max }\right)$ as well as the AUC normalised to $1 \mathrm{mg}$ of irinotecan $\left(\mathrm{AUC}_{\mathrm{N}}\right)$ 
were calculated for SN-38. A three- and two-compartment model was used for irinotecan and $\mathrm{SN}-38$, respectively.

\section{Statistical considerations}

Using the hypothesis that the response rate in Groups B and C would be $20 \%$, a total of 64 patients in each of these groups were required to yield a confidence interval (CI) band of $\leqslant 20 \%$. For the reference group (Group A), the number of subjects randomised was half that of Groups B and C. The 95\% CIs were estimated for response, using the exact method. Confidence intervals on median values were estimated using the method described by Brookmeyer and Crowley (Simon et al, 1985). Descriptive statistics only were used for the pharmacokinetic parameters in each group.

\section{RESULTS}

\section{Patients}

A total of 164 patients entered the study: 36 in Group A, 62 in Group B and 66 in Group C (Table 1). The majority of patients $(\geqslant 97 \%)$ had received surgery and $20-30 \%$ had received radiotherapy and/or prior adjuvant chemotherapy. Based on the assessment of baseline risk factors previously described, 23 (35\%) patients in Group C were assigned to receive a starting dose of $250 \mathrm{mg} \mathrm{m}^{-2}$ irinotecan, $37(56 \%)$ patients to $350 \mathrm{mg} \mathrm{m}^{-2}$ and six (9\%) patients to $500 \mathrm{mg} \mathrm{m}^{-2}$.

A total of $144(88 \%)$ patients $(31,51$ and 62 in Groups A, B and $\mathrm{C}$, respectively) were eligible and evaluable for the efficacy analyses. Nine patients were ineligible due to major protocol violations ( $>1$ line of palliative chemotherapy, and past or concurrent history of neoplasm other than colorectal adenocarcinoma in one patient) and 12 patients (not mutually exclusive) were nonevaluable for response. Early discontinuation because of adverse events rendered eight patients nonevaluable.

\section{Extent of exposure to irinotecan}

The median dose intensity of irinotecan was similar in the three arms: $114.21 \mathrm{mg} \mathrm{m}^{-2}$ week $^{-1}$ (95\% CI 76.14-119.21) in Group A, $101.36 \mathrm{mg} \mathrm{m}^{-2}$ week $^{-1}(95 \%$ CI $68.22-158.17)$ in Group B and $106.69 \mathrm{mg} \mathrm{m}^{-2}$ week $^{-1} \quad(95 \%$ CI 67.11-170.93) in Group C. However, the median cumulative dose was higher in Group A $\left(1948.80 \mathrm{mg} \mathrm{m}^{-2}\right)$ than in Groups B $\left(1564.26 \mathrm{mg} \mathrm{m}^{-2}\right)$ and $C$ $\left(1326.77 \mathrm{mg} \mathrm{m}^{-2}\right)$, possibly due to the longer median treatment time in this group (18 weeks, compared with 16 and 13 weeks in Groups B and C, respectively).

The percentage of cycles delivered at doses of 250, 350 and $500 \mathrm{mg} \mathrm{m}^{-2}$ were as follows: 3,92 and $0 \%$ (as this was not an option) in Group A; 41, 30 and 27\% in Group B; and 33, 51 and $8 \%$ in Group C. A few cycles in each group were given at intermediate doses or at doses above $525 \mathrm{mg} \mathrm{m}^{-2}$.

In Group B, the only dose escalation option, $63 \%$ of patients had at least one dose escalation from the $250 \mathrm{mg} \mathrm{m}^{-2}$ start dose.

More than $80 \%$ of patients in each group did not require dose reduction. A total of $36-40 \%$ of patients experienced a cycle delay (Table 2). Although the majority of dose reductions in each group were made for treatment-related reasons (mostly nonhaematological adverse events across all arms), the majority of cycle delays occurred for reasons unrelated to treatment.

\section{Efficacy}

Response rate In the total (ITT) patient population $(n=164)$, the overall response rates were 8,13 and $9 \%$ in Groups A, B and C, respectively (Table 3 ). There were no CRs. Tumour growth control rates were higher in Groups $\mathrm{A}$ and $\mathrm{B}$ and the rates of progressive disease were lower, compared with Group C (Table 3). The pattern of response across the groups was maintained in the per-protocol (eligible and evaluable) patient population $(n=144)$, with overall response rates (no CR) of 10, 16 and $10 \%$ in Groups A, B and C, respectively. Corresponding tumour growth control rates were 61 , 65 and $53 \%$.

Responses occurred at all dose levels (Table 3). However, there were only two responses at the $250 \mathrm{mg} \mathrm{m}^{-2}$ dose of irinotecan, both in Group C. Although it is difficult to interpret the data based on the small patient numbers in this study, they suggest that starting patients on a dose of $250 \mathrm{mg} \mathrm{m}^{-2}$ was not beneficial.

The median duration of response and TTP were significantly longer in Groups A and B compared with Group C $(P=0.030)$ (Table 3). Despite a trend towards a shorter TTF and median overall survival in Group C, there were no significant differences across the arms for these parameters.

\section{Safety and tolerability}

All patients were evaluable for safety. At least one adverse event was reported in all patients. However, grade 3-4 adverse events possibly or probably related to the study treatment were reported in less than half of the patients in each group (Table 4). Most of these were related to haematological or gastrointestinal (GI) events (Table 4). Grade 3-4 neutropenia with fever or infection was infrequent. Although anaemia was common, it was infrequently reported at grade 3-4 level of severity (Table 4). Diarrhoea was the most common GI event, occurring in $85 \%$ of patients, although grade 3-4 diarrhoea was less frequent $(31,21$ and $27 \%$ in Groups $\mathrm{A}, \mathrm{B}$ and $\mathrm{C}$, respectively) (Table 4). There were no significant between-group differences for any of the adverse events reported. In addition, analysis of adverse events at the different dose levels showed no consistent evidence that toxicity increased with increasing dosage. There was no difference between the three treatment groups for the number of patients reporting $\geqslant 1$ grade 3-4 adverse event considered to be possibly or probably treatment-related (Group A, 42\%; Group B, 48\%; Group C, 49\%). Overall, 74 serious adverse events considered possibly or probably related to study medication occurred in 39 patients.

\section{Treatment discontinuations}

At the designated study end date, 159 (96.95\%). patients had discontinued treatment (Group A, 97\%; Group B, 95\%; Group C, 99\%) (Table 5). Disease progression resulted in proportionately fewer discontinuations in Group B (57\%) than in Groups A (72\%) and $C(80 \%)$, and included fatalities arising from progressive disease (one patient in each of Groups A and B, and two patients in Group C). There was also one fatality: a case of aspiration pneumonia secondary to vomiting in a patient in Group B receiving the first cycle of irinotecan $250 \mathrm{mg} \mathrm{m}^{-2}$. Five (42\%) of the patients who discontinued treatment from Group B were receiving the $250 \mathrm{mg} \mathrm{m}^{-2}$ dose option during cycle 1 at the time of withdrawal. Adverse events leading to discontinuations are listed in Table 5.

\section{Pharmacokinetic parameters}

The principal pharmacokinetic parameters for irinotecan and $\mathrm{SN}$ 38 measured in 29 assessable patients are presented in Table 6. The mean total body clearance values of irinotecan were similar across all three groups and no relevant differences in dose-normalised exposure were seen. Exposure to irinotecan and SN-38 increased proportionally over the $250-500 \mathrm{mg} \mathrm{m}^{-2}$ irinotecan dose range. In the population pharmacokinetic analysis, exposure to irinotecan appeared to be increased in patients with PS 1 or 2 , and in patients with high alkaline phosphate levels. 
Table I Patient demographics and baseline characteristics

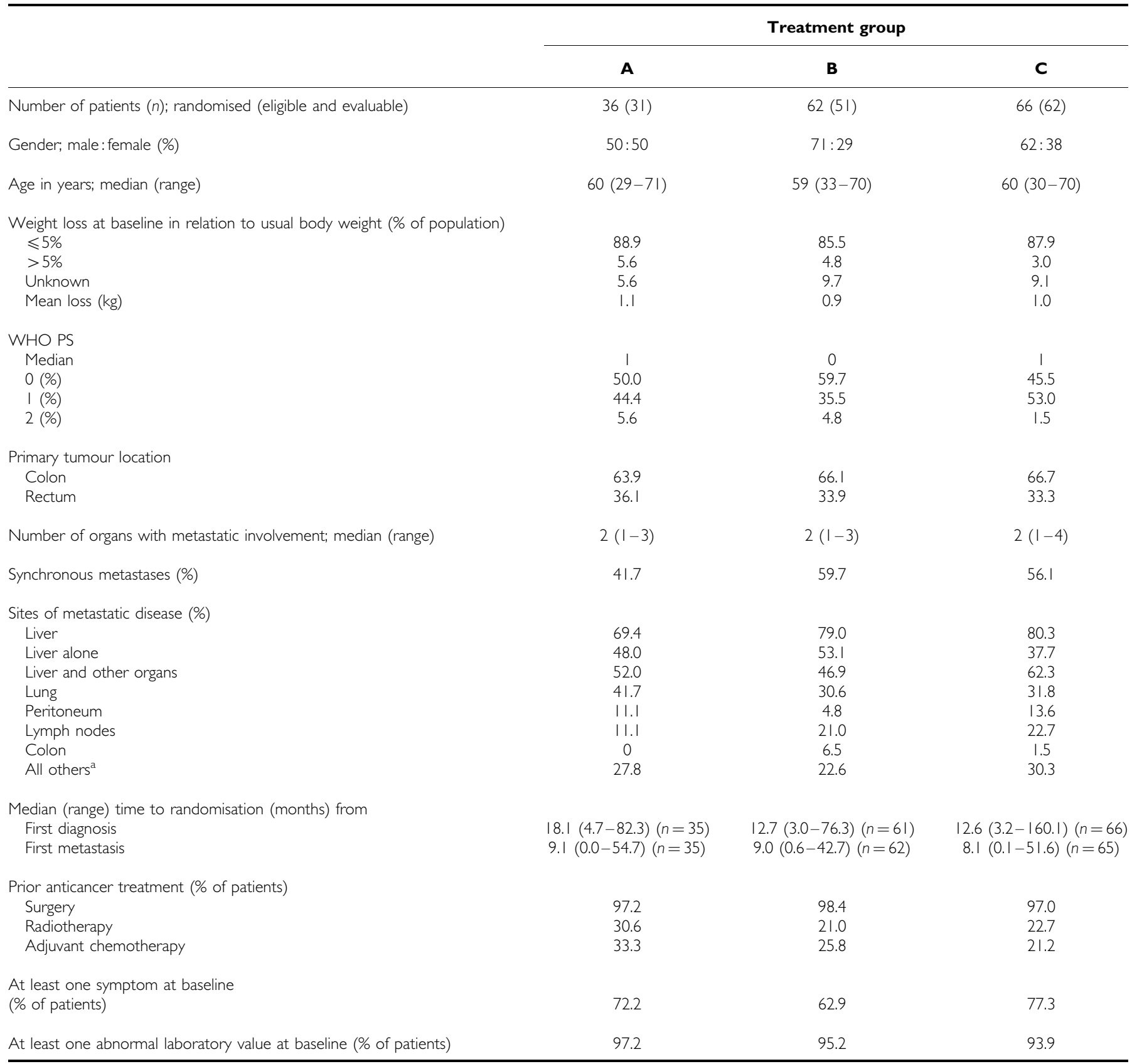

a Soft tissue, bone, adrenal, pelvis, abdomen, pleura, retroperitoneum, spleen, mediastinum, skin. WHO, World Health Organization.

\section{DISCUSSION}

The results of this phase II study confirm the activity of singleagent irinotecan in patients with metastatic colorectal cancer who have failed previous therapy with 5-FU. All three treatment strategies investigated were active and demonstrated acceptable tolerability patterns. Although almost all patients in the study had $\geqslant 1$ adverse event, less than half of the patients in each treatment strategy had grade 3-4 toxicity.

The main aim of this study was to determine the optimal irinotecan dosing regimen for the treatment of this population, with the primary end point being response rate. The highest overall response rate was seen in patients in Group B (13\%). In this group, four $(21 \%)$ of the 19 patients receiving irinotecan
$500 \mathrm{mg} \mathrm{m}^{-2}$ achieved a response. There was little difference in the overall response rates in Groups A and C (8 and 9\%, respectively). An interesting observation in this study was the relatively higher rate of progressive disease in Group C (44\%) compared with Groups A and B (36 and 31\%). None of the differences in response rate between the groups were statistically significant. It is worth mentioning that the response rate observed in Group A was unusually low, and less than that seen in published studies of similar populations of patients treated with the same schedule (Rougier et al, 1997; Van Cutsem et al, 1999). This may be due to changes in first-line treatment that have occurred in recent years; compared with patients treated in earlier studies, those in the present study may have been more heavily pretreated with 5FU and oxaliplatin in the first-line setting, thus making them more 


\begin{tabular}{|c|c|c|c|}
\hline & \multicolumn{3}{|c|}{ Treatment group } \\
\hline & $\mathbf{A}$ & B & C \\
\hline Number of treatment cycles & 216 & 370 & 333 \\
\hline Median (range) number of cycles & $6(1-24)$ & $5(|-2|)$ & $4(1-15)$ \\
\hline Median (range) treatment duration (weeks) & $18(3-78)$ & $16(3-64)$ & $13(3-46)$ \\
\hline \multicolumn{4}{|l|}{ Cycles by dose (\% of cycles) $)^{a}$} \\
\hline $350 \mathrm{mg} \mathrm{m}^{-2}$ & 92 & 30 & 51 \\
\hline $500 \mathrm{mg} \mathrm{m}^{-2}$ & - & 27 & 8 \\
\hline Median actual dose intensity $\left(\mathrm{mg} \mathrm{m}^{-2}\right.$ week $\left.^{-1}\right)(95 \% \mathrm{Cl})$ & $1 \mid 4.21(76.14-119.21)$ & $101.3668 .22-158.17)$ & $106.69(67.11-170.93)$ \\
\hline Median cumulative dose $\left(\mathrm{mg} \mathrm{m}^{-2}\right)(95 \% \mathrm{Cl})$ & $1948.80(3 \mid 4.65-8373.08)$ & $1564.26(247.52-10100.00)$ & | $326.77(249.73-4899.13)$ \\
\hline At least one dose increase (\% of patients) & - & 63 & - \\
\hline \multicolumn{4}{|l|}{ At least one dose reduction ${ }^{\mathrm{b}}$} \\
\hline$\%$ of patients & 17 & 15 & 17 \\
\hline
\end{tabular}

a Some cycles were administered at intermediate doses. ${ }^{\mathrm{b}}$ For any reason (see text).

Table 3 Efficacy results

\begin{tabular}{|c|c|c|c|c|}
\hline Parameter & Group A $(n=36)$ & Group B $(n=62)$ & Group C $(n=66)$ & $P$-value ${ }^{a}$ \\
\hline Overall response rate, $\%(95 \% \mathrm{Cl})^{\mathrm{b}}$ Per protocol & $10(2.0-25.8)$ & $16(7.0-28.6)$ & $10(3.6-19.9)$ & \\
\hline $500 \mathrm{mg} \mathrm{m}^{-2 c}$ & - & $(4 / 19) 21 \%$ & $(0 / 6) 0 \%$ & NC \\
\hline Tumour growth control rate (\%) & $58 \%$ & $60 \%$ & $50 \%$ & NC \\
\hline Progressive disease (\%) & $36 \%$ & $31 \%$ & $44 \%$ & NC \\
\hline Median TTF (months) & 3.7 & 3.4 & 2.5 & NS \\
\hline Median overall survival (months) & 12.5 & 12.1 & 10.9 & NS \\
\hline
\end{tabular}

Results are presented for the ITT population, unless otherwise stated. ${ }^{a} \mathrm{~A}$ vs $\mathrm{C}$ and $\mathrm{B}$ vs $\mathrm{C}$. ${ }^{\mathrm{b}}$ There were no $\mathrm{CRs} .{ }^{\mathrm{c}}$ Response rate is expressed as a percentage of patients treated at that dose level as their highest dose in each group. Cl, confidence interval; NC, not calculated; NS, not significant.

chemotherapy resistant. Despite the lower response rate in Group $\mathrm{A}$, it is within the CIs of previous studies and so can be considered representative.

The lack of a significant difference in overall response rates between the groups may reflect the fact that the median dose intensity of irinotecan delivered was relatively constant across the three groups, despite a proportion of patients in Groups B (34\%) and $C(9 \%)$ receiving an irinotecan dose of $500 \mathrm{mg} \mathrm{m}^{-2}$. This finding is probably due mainly to the fact that a disproportionate number of patients (more than one-third) in each of Groups B and $\mathrm{C}$ never received a dose of more than $250 \mathrm{mg} \mathrm{m}^{-2}$, and so were possibly underdosed. The likelihood of underdosing in Groups B and $\mathrm{C}$ is supported by the observation that only $6 \%$ of patients in Group A required dose reduction from 350 to $250 \mathrm{mg} \mathrm{m}^{-2}$.

There were no significant differences between Groups A and B in TTP or overall survival. This may be due to an insufficient powering of the study and/or too small a difference in response rates. A previous meta-analysis conducted in patients with advanced colorectal cancer reported that only large differences in response rate correspond to a significant difference in TTP (Buyse et al, 2000). Both TTP and duration of response were significantly shorter in Group C than in Groups A and B, and there was also a trend for a shorter overall survival in this group. The relatively poor efficacy seen in Group $\mathrm{C}$ may have been due to a combination of underdosing (i.e. a significant number of patients receiving irinotecan $250 \mathrm{mg} \mathrm{m}^{-2}$ ) and the small number of patients who received the high dose of irinotecan $\left(500 \mathrm{mg} \mathrm{m}^{-2}\right.$ ) (six patients or $9 \%$ ).

There was a trend towards a better safety profile in Group B. Grade 3-4 neutropenia was $31 \%$ in Group B, $47 \%$ in A and $44 \%$ in Group B. Similarly, there was less grade 3-4 diarrhoea in Group B as compared with Groups A and C (21 vs 31 and 27\%, respectively), despite $34 \%$ of patients receiving the highest irinotecan dose. We cannot exclude the contribution to this difference of imbalances in gender ratio (more male patients in Group B) and PS (more patients with PS $=0$ in Group B). However, it is possible that the results reflect the aim of the strategy adopted in Group B, which was to avoid subjecting patients to higher doses than they were able to tolerate. Indeed 10 out of 12 patients in Group B who withdrew from the study due to treatment-related adverse events received the lowest dose of irinotecan $\left(250 \mathrm{mg} \mathrm{m}^{-2}\right)$ and therefore would not have tolerated an increased dose of irinotecan. However, it should also be noted that severe toxicity leading to treatment discontinuation occurred more frequently in Group B despite the low dose given to all patients in the first cycle. In Group C, despite the strategy of basing the initial irinotecan 
Table 4 Adverse events

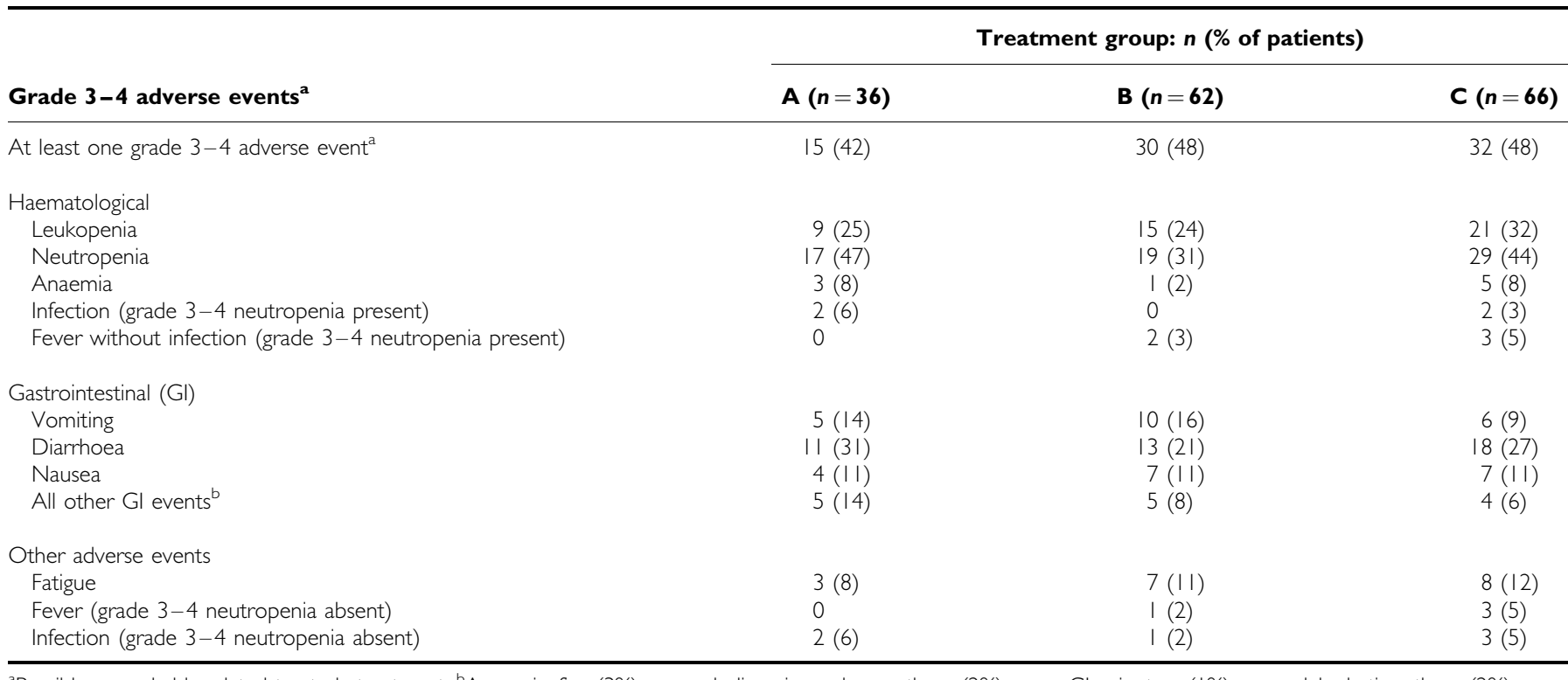

a Possibly or probably related to study treatment. ${ }^{\text {b} A n o r e x i a, ~ f i v e ~(3 \%) ~ c a s e s ; ~ c h o l i n e r g i c ~ s y n d r o m e, ~ t h r e e ~(2 \%) ~ c a s e s ; ~ G l ~ p a i n, ~ t w o ~(I \%) ~ c a s e s ; ~ d e h y d r a t i o n, ~ t h r e e ~(2 \%) ~ c a s e s ; ~}$ stomatitis, one (I\%) case.

Table 5 Patient discontinuations

\begin{tabular}{|c|c|c|c|}
\hline & \multicolumn{3}{|c|}{ Treatment group: $n$ ( $\%$ of patients) } \\
\hline & $A(n=36)$ & B $(n=62)$ & $C(n=66)$ \\
\hline Total treatment discontinuations & $35(97)$ & $59(95)$ & $65(99)$ \\
\hline \multicolumn{4}{|l|}{ Nonfatal reasons } \\
\hline Progressive disease & $25(69)$ & $34(55)$ & $51(77)$ \\
\hline Fatigue & I (3) & $3(5)$ & $2(3)$ \\
\hline Vomiting & $1(3)$ & $3(5)$ & $2(3)$ \\
\hline Diarrhoea & - & $4(7)$ & $2(3)$ \\
\hline Nausea & - & $2(3)$ & $2(3)$ \\
\hline Neutropenia & - & $2(3)$ & I (2) \\
\hline Febrile neutropenia & - & $2(3)$ & - \\
\hline Neutropenic infection & I (3) & - & - \\
\hline \multicolumn{4}{|l|}{ Fatal reasons } \\
\hline Death due to treatment-related adverse events & - & I (2) & - \\
\hline Death due to progressive disease & I (3) & $1(2)$ & $2(3)$ \\
\hline Cardio-respiratory failure & - & - & I (2) \\
\hline
\end{tabular}

${ }^{a}$ Not mutually exclusive. Patients may have discontinued treatment for more than one adverse event reason. ${ }^{b}$ Group B: aggravation reaction, two (3\%) cases; anorexia, one (2\%) case; dehydration, one (2\%) case; small bowel obstruction, one (2\%) case. Group C: anorexia, one (2\%) case.

dose on predetermined risk factors, patients administered the $250 \mathrm{mg} \mathrm{m}^{-2}$ dose demonstrated higher rates of grade 3-4 anaemia and diarrhoea compared with those receiving the 350 and $500 \mathrm{mg} \mathrm{m}^{-2}$ doses.

This study demonstrates that intrapatient dose escalation based on toxicity in the preceding cycle dose, as practised in Group B, is feasible. Although the increase in the response rate over the whole group was modest compared with the standard irinotecan dose, clinical benefit may be seen in those patients who are able to receive 350 and $500 \mathrm{mg} \mathrm{m}^{-2}$, which, in this study, was associated with a response rate of 25 and $21 \%$, respectively. The findings of our study in pretreated patients are in agreement with those of a nonrandomised study in previously untreated patients (Ychou et al, 2002): the greater proportion of patients who are able to receive the higher dose and the higher response rate achieved in the latter study compared with our study is probably a reflection of interstudy differences in the starting dose, dose escalation guidelines and in the study population (previous treatment compared with no previous treatment) 
Pharmacokinetic profiles of irinotecan and SN-38 at different doses of irinotecan

\begin{tabular}{|c|c|c|c|c|c|c|}
\hline \multirow[b]{2}{*}{ Cycle } & \multicolumn{2}{|l|}{ Arm A } & \multicolumn{2}{|l|}{ Arm B } & \multicolumn{2}{|c|}{ Arm C } \\
\hline & । & | & 2 & 3 & 1 & । \\
\hline No. of patients & 6 & 13 & 8 & 5 & 5 & 5 \\
\hline Dose $(n)\left(\mathrm{mg} \mathrm{m}^{-2}\right)$ & 350 & 250 & 350 & $300(1) / 500(4)$ & 250 & 350 \\
\hline \multicolumn{7}{|l|}{ Irinotecan } \\
\hline Infusion duration (h) & $0.5-1.5$ & $0.5-1.5$ & $0.5-1.0$ & $0.5-1.1$ & $0.5-1.6$ & $0.5-1.1$ \\
\hline$C_{\max }\left(\left.m g\right|^{-1}\right)$ & $5.88(4.79-9.18)$ & $4.55(3.05-5.87)$ & $6.12(5.33-6.70)$ & $8.40(4.57-8.62)$ & $3.61(3.26-4.56)$ & $7.13(5.10-7.79)$ \\
\hline $\operatorname{A\cup C}\left(\mathrm{mghl}^{-1}\right)$ & $32.7(14.3-36.4)$ & $20.5(11.6-30.9)$ & $27.8(20.4-39.2)$ & $44.7(28.0-50.6)$ & $19.7(15.3-29.0)$ & $33.4(22.9-46.3)$ \\
\hline Clearance $\left(\mathrm{I} \mathrm{h}^{-2}\right)$ & $9.3(8.4-21.3)$ & $10.6(7.0-18.9)$ & $10.9(8.2-14.9)$ & $9.1(5.9-15.6)$ & $10.6(7.53-14.4)$ & $9.03(6.55-13.3)$ \\
\hline \multicolumn{7}{|l|}{ SN-38 } \\
\hline Median $t_{\max }(\mathrm{h})$ & $0.7(0.6-1.5)$ & $0.6(0.5-1.6)$ & $0.6(0.5-1.0)$ & $0.7(0.6-1.1)$ & $1.5(0.6-1.6)$ & $1.0(0.6-1.1)$ \\
\hline$C_{\max }\left(\left.\mu g\right|^{-1}\right)$ & $61.9(33.5-86.7)$ & $49.7(24.0-138.0)$ & $58.7(38.0-168.0)$ & $80.7(34.9-97.3)$ & $40.6(33.9-962)$ & $67.9(50.2-135)$ \\
\hline $\mathrm{A} \cup C\left(\mu g \mathrm{hl}^{-1}\right)$ & $668(362-1110)$ & $676(324-1140)$ & $960(546-1300)$ & $1420(609-1610)$ & $595(403-903)$ & $768(579-1395)$ \\
\hline $\operatorname{AUC}_{N}{ }^{a}\left(\mu g h I^{-1}\right)$ & $1.9(1.1-2.9)$ & $2.4(1.3-5.0)$ & $2.6(1.6-4.4)$ & $2.6(1.3-5.1)$ & $2.0(1.5-3.2)$ & $2.5(1.5-4.4)$ \\
\hline
\end{tabular}

${ }^{a}$ Normalised to I mg irinotecan dose. Data are expressed as median $(95 \% \mathrm{Cl})$ unless otherwise stated. AUC, area under the plasma concentration-time curve; $C_{\text {max }}$, maximum plasma concentration; $t_{\max }$, time to reach maximum plasma concentration.

In contrast with the feasibility of the strategy in Group B, the use of dose optimisation according to the baseline risk characteristics identified in our study protocol (as practised in Group C) appeared not to be an appropriate approach. This may be because the risk characteristics identified were not valid in this setting or that the algorithm for dose assignment was not relevant. Further investigation is required to clarify this.

In conclusion, the data from our randomised phase II study suggest that individual dose optimisation based on toxicity in the preceding cycle is feasible and merits further investigation. Increasing the dose of irinotecan to $500 \mathrm{mg} \mathrm{m}^{-2}$ can be of benefit in selected patients. It will be necessary to identify the most appropriate starting dose, as the dose of $250 \mathrm{mg} \mathrm{m}^{-2}$ used in this

\section{REFERENCES}

Abigerges D, Chabot GG, Armand JP, Herait P, Gouyette A, Gandia D (1995) Phase I and pharmacologic studies of the camptothecin analog irinotecan administered every 3 weeks in cancer patients. J Clin Oncol 13: $210-221$

Buyse M, Thirion P, Carlson RW, Burzykowski T, Molenberghs G, Piedbois P (2000) Relation between tumour response to first-line chemotherapy and survival in advanced colorectal cancer: a meta-analysis. MetaAnalysis Group in Cancer. Lancet 356: 373-378

Canal P, Gay C, Dezeuze A, Douillard JY, Bugat R, Brunet R, Adenis A, Herait P, Lokiec F, Mathieu-Boue A (1996) Pharmacokinetics and pharmacodynamics of irinotecan during a phase II clinical trial in colorectal cancer. Pharmacology and Molecular Mechanisms Group of the European Organization for Research and Treatment of Cancer. J Clin Oncol 14: 2688-2695

Chabot GG, Abigerges D, Catimel G, Culine S, de Forni M, Extra JM, Mahjoubi M, Herait P, Armand JP, Bugat R (1995) Population pharmacokinetics and pharmacodynamics of irinotecan (CPT-11) and active metabolite SN-38 during phase I trials. Ann Oncol 6: $141-151$

Cunningham D, Maroun J, Vanhoefer U, Van Cutsem E (2001) Optimizing the use of irinotecan in colorectal cancer. Oncologist 6(Suppl 4): $17-23$

Cunningham D, Pyrhonen S, James RD, Punt CJ, Hickish TF, Heikkila R, Johannesen TB, Starkhammar H, Topham CA, Awad L, Jacques C, Herait P (1998) Randomised trial of irinotecan plus supportive care versus supportive care alone after fluorouracil failure for patients with metastatic colorectal cancer. Lancet 352: 1413-1418

Freyer G, Rougier P, Bugat R, Droz JP, Marty M, Bleiberg H, Mignard D, Awad L, Herait P, Culine S, Trillet-Lenoir V (2000) Prognostic factors for tumour response, progression-free survival and toxicity in metastatic study was possibly too conservative. Data from pharmacogenomic research are likely to be useful in the future for identifying the most appropriate starting dose of irinotecan for individual patients.

\section{ACKNOWLEDGEMENTS}

The following additional investigators contributed to this study: $\mathrm{F}$ Cavalli (Switzerland), A Etxeberria (Spain), C Focan (Belgium), H Honegger (Switzerland), R Mathijs (Belgium), M Pestalozzi (Switzerland), M Symann (Belgium) and A Tres (Spain). colorectal cancer patients given irinotecan (CPT-11) as second-line chemotherapy after 5FU failure. CPT-11 F205, F220, F221 and V222 study groups. Br J Cancer 83: 431-437

Mathijssen RH, Verweij J, de Jonge MJ, Nooter K, Stoter G, Sparreboom A (2002) Impact of body-size measures on irinotecan clearance: alternative dosing recommendations. J Clin Oncol 20: 81-87

Merrouche Y, Extra JM, Abigerges D, Bugat R, Catimel G, Suc E, Marty M, Herait P, Mahjoubi M, Armand JP (1997) High dose-intensity of irinotecan administered every 3 weeks in advanced cancer patients: a feasibility study. J Clin Oncol 15: 1080-1086

Pitot HC, Wender DB, O'Connell MJ, Schroeder G, Goldberg RM, Rubin J, Mailliard JA, Knost JA, Ghosh C, Kirschling RJ, Levitt R, Windschitl HE (1997) Phase II trial of irinotecan in patients with metastatic colorectal carcinoma. J Clin Oncol 15: 2910-2919

Rothenberg ML, Cox JV, DeVore RF, Hainsworth JD, Pazdur R, Rivkin SE, Macdonald JS, Geyer Jr CE, Sandbach J, Wolf DL, Mohrland JS, Elfring GL, Miller LL, Von Hoff DD (1999) A multicenter, phase II trial of weekly irinotecan (CPT-11) in patients with previously treated colorectal carcinoma. Cancer 85: 786-795

Rothenberg ML, Eckardt JR, Kuhn JG, Burris III HA, Nelson J, Hilsenbeck SG, Rodriguez GI, Thurman AM, Smith LS, Eckhardt SG, Weiss GR, Elfring GL, Rinaldi DA, Schaaf LJ, Von Hoff DD (1996) Phase II trial of irinotecan in patients with progressive or rapidly recurrent colorectal cancer. J Clin Oncol 14: 1128-1135

Rougier P, Bugat R, Douillard JY, Culine S, Suc E, Brunet P, Becouarn Y, Ychou M, Marty M, Extra JM, Bonneterre J, Adenis A, Seitz JF, Ganem G, Namer M, Conroy T, Negrier S, Merrouche Y, Burki F, Mousseau M, Herait P, Mahjoubi M (1997) Phase II study of irinotecan in the treatment of advanced colorectal cancer in chemotherapy-naive patients 
Optimisation of irinotecan dosing

E Van Cutsem et a

and patients pretreated with fluorouracil-based chemotherapy. J Clin Oncol 15: 251-260

Rougier P, Van Cutsem E, Bajetta E, Niederle N, Possinger K, Labianca R, Navarro M, Morant R, Bleiberg H, Wils J, Awad L, Herait P, Jacques C (1998) Randomised trial of irinotecan versus fluorouracil by continuous infusion after fluorouracil failure in patients with metastatic colorectal cancer. Lancet 352: 1407-1412

Shimada Y, Yoshino M, Wakui A, Nakao I, Futatsuki K, Sakata Y, Kambe M, Taguchi T, Ogawa N (1993) Phase II study of CPT-11, a new camptothecin derivative, in metastatic colorectal cancer. CPT-11 Gastrointestinal Cancer Study Group. J Clin Oncol 11: 909-913

Simon R, Wittes RE, Ellenberg SS (1985) Randomized phase II clinical trials. Cancer Treat Rep 69: 1375-1381
Van Cutsem E, Cunningham D, Ten Bokkel Huinink WW, Punt CJ, Alexopoulos CG, Dirix L, Symann M, Blijham GH, Cholet P, Fillet G, Van Groeningen C, Vannetzel JM, Levi F, Panagos G, Unger C, Wils J, Cote C Blanc C, Herait P, Bleiberg H (1999) Clinical activity and benefit of irinotecan (CPT-11) in patients with colorectal cancer truly resistant to 5-fluorouracil (5-FU). Eur J Cancer 35: 54-59

Xie R, Mathijssen RH, Sparreboom A, Verweij J, Karlsson MO (2002) Clinical pharmacokinetics of irinotecan and its metabolites: a population analysis. J Clin Oncol 20: 3293-3301

Ychou M, Raoul JL, Desseigne F, Borel C, Caroli-Bosc FX, Jacob JH, Seitz JF, Kramar A, Hua A, Lefebvre P, Couteau C, Merrouche Y (2002) Highdose, single-agent irinotecan as first-line therapy in the treatment of metastatic colorectal cancer. Cancer Chemother Pharmacol 50: 383-391 